\title{
A ABORDAGEM DOS GÊNEROS DO DISCURSO NAS PROPOSTAS DE PRODUÇÃO DE TEXTOS ESCRITOS EM LIVRO DIDÁTICO DE PORTUGUÊS ${ }^{1}$
}

\author{
Alyne Barbosa Lima ${ }^{2}$ \\ Mayara Macedo Assis ${ }^{3}$ \\ Silvio Ribeiro da Silva ${ }^{4}$
}

\begin{abstract}
RESUMO Neste artigo, objetivamos mostrar os resultados de um estudo que teve como alvos: (a) analisar se as propostas de produção de textos escritos apresentadas pela coleção de livro didático de Português (LDP) 'Português Linguagens', de William Roberto Cereja e Thereza Cochar Magalhães, $6^{\circ}$ a $9^{\circ}$ ano, trabalha as condições de produção do texto (locutor, interlocutor, gênero, suporte, contexto de circulação); (b) averiguar a (in)existência da abordagem em espiral no tratamento dado aos gêneros do discurso propostos para produção; e (c) verificar a (in)existência de variedade de gêneros do discurso propostos para produção de textos escritos. Para isso, buscamos apoio nos pressupostos teóricos da Linguística Aplicada (LA), cuja preocupação central está nos problemas decorrentes do uso da linguagem em um determinado contexto. Os dados nos mostram que existe uma boa abordagem das condições de produção, bem como variedade de gêneros propostos, representando pontos positivos da coleção. Porém, ocorre pouca incidência da abordagem em espiral, o que pode trazer menos impacto positivo para a aprendizagem do aluno e para a prática de produção de textos mais significativos, interferindo negativamente nos seus letramentos.
\end{abstract}

Palavras-chave: Produção de texto escrito. Gêneros do discurso. Livro didático de Português.

\section{THE APPROACH OF SPEECH GENDERS IN THE PROPOSALS FOR THE PRODUCTION OF WRITTEN TEXTS IN THE PORTUGUESE TEXTBOOK $^{5}$}

\begin{abstract}
In this article, we aim to show the results of a study that had the following objectives: (a) to analyze if the proposals for the production of written texts presented by the Portuguese textbook collection 'Português Linguagens', by William Roberto Cereja and Thereza Cochar Magalhães, $6^{\text {th }}$ to $9^{\text {th }}$ year, works with the production conditions of the text (speaker, interlocutor, gender, support, circulation context); (b) to ascertain the (in)existence of the spiral approach in the treatment given to the speech genres proposed for production; and (c) to verify the (in)existence of a variety of speech genres proposed for the production of written texts. For this, we seek support in the theoretical \footnotetext{
de Estudos da Linguagem: análise, descrição e ensino (***/CNPq).

${ }^{2}$ Graduanda em Letras Português. Bolsista Cnpq. Universidade Federal de Goiás-Regional Jataí

${ }^{3}$ Graduanda em Letras Português. Universidade Federal de Goiás-Regional Jataí

${ }^{4}$. Graduado em Letras Português (UFG). Mestre em Linguistica (UFU). Doutor em Linguística

Aplicada(UNICAMP) Professor Adjunto 3 (UFG/REJ)

${ }^{5}$ This study contributes to academic research on the subject and also to those carried out within the Group of Studies on Textbooks, Teaching and Evaluation - GEMDAV (*** / CNPq), as well as the Group of Studies of Language: analysis, description and teaching $(* * * / \mathrm{CNPq})$.
}

${ }^{1}$ Este estudo contribui com as pesquisas acadêmicas sobre o tema e ainda com aqueles realizados dentro do Grupo de Estudos sobre Materiais Didáticos, Ensino e Avaliação - GEMDAV (***/CNPq), bem como do Grupo
\end{abstract}


Volume 14, número 1, ano 2018.

assumptions of Applied Linguistics, whose central concern is in the problems consequent from the use of language in a given context. The data shows us that there is a good approach of the production conditions, as well as the variety of genres proposed, representing positive points of the collection. However, there is little incidence of the spiral approach, which can have less positive impact for student learning and for the practice of producing more significant texts, interfering negatively in their literacies.

Keywords: Speech genres. Production of written text. Portuguese textbook.

\section{INTRODUÇÃO}

Há controvérsias acerca da utilização do livro didático (LD) na sala de aula. Por um lado, é uma ferramenta que, se bem empregada, contribui enormemente para o processo de ensino e aprendizagem. Por outro, pode deixar de ser um auxílio e se tornar o único instrumento usado para o planejamento das aulas, assim como o único material de estudo e leitura com o qual os alunos têm contato (SILVA et al, 1996). Em escolas com poucos recursos e professores de baixa formação - que, infelizmente, ainda é o caso de grande parte das instituições de ensino brasileiras -, a segunda realidade é a mais comum. Considerando que a escola tem a função de formar bons leitores e produtores de textos, torna-se de extrema relevância a verificação da qualidade das propostas de produção de textos escritos. Esse é o principal motivo da realização de uma pesquisa sobre as propostas de produção de textos escritos apresentadas ao aluno pela coleção de LDP 'Português Linguagens', de William Roberto Cereja e Thereza Cochar Magalhães, de $6^{\circ}$ a $9^{\circ}$ ano, Atual Editora.

A escolha pela coleção se justifica pelo fato de figurar entre as mais adotadas em todo o território nacional. Para fins de ilustração, em relação ao Programa Nacional do Livro Didático (PNLD) de 2017, a coleção 'Português Linguagens' teve 5.792 .929 (cinco milhões, setecentos e noventa e dois mil, novecentos e vinte e nove) exemplares adquiridos pelo Fundo Nacional de Desenvolvimento da Educação (FNDE) ${ }^{6}$, sendo a coleção de Língua Portuguesa mais adquirida no Brasil. Com um índice de adoção tão alto, representando um investimento também alto por parte do Governo Federal, são necessárias pesquisas que se debrucem sobre os objetos de ensino escolarizados por ela.

\footnotetext{
${ }^{6}$ FONTE: http://www.fnde.gov.br/programas/programas-do-livro/livro-didatico/dados-estatisticos. Acesso em 14 de julho de 2017.
} 
Volume 14, número 1, ano 2018.

O estudo que deu origem a este artigo foi realizado a partir dos pressupostos da Linguística Aplicada (LA), as quais se preocupam com problemas decorrentes do uso da linguagem em um determinado contexto, afinal, como afirma Rajagopalan (2006, p. 163), “a atividade linguística é uma prática social. Sendo assim, qualquer tentativa de analisar a língua de forma isolada, desvinculada das condições sociais dentro das quais ela é usada, cria apenas um objeto irreal".

Segundo Moita Lopes (1996), é importante se definir os paradigmas sob os quais a LA atua para, assim, estabelecer um percurso de investigação. De acordo com o mesmo autor, faz-se necessária uma pesquisa de base interpretativista, que vai além do método a princípio utilizado pelos linguistas - de natureza positivista - e é mais adequado ao caráter subjetivo inerente ao objeto de estudo das Ciências Sociais, afinal, "o foco neste tipo de pesquisa é no processo de uso da linguagem" (p. 22).

A pesquisa também se volta para a análise de conteúdo, método ressaltado por Bardin (2009) como sendo uma técnica de análise sistemática e objetiva que não visa à descrição de um conteúdo em si, e sim ao conhecimento que será inferido após a mesma. O conteúdo é tratado como uma manifestação de algo a mais - contexto de produção e recepção, por exemplo - que deve ser descoberto pelo pesquisador. Conforme a autora (2009, p. 41), a inferência é a fase intermediária entre a descrição e a interpretação, e o trabalho do analista consiste em "compreender o sentido da comunicação (como se fosse o receptor normal), mas também, e principalmente, desviar o olhar para uma outra significação, uma outra mensagem entrevista através, ou ao lado, da mensagem primeira".

Para proceder à essa pesquisa, o livro didático (LD) foi submetido a uma análise documental, que é a condensação das informações de um corpus para o armazenamento e posterior consulta, visando a facilitar seu manuseio durante a análise. Podemos afirmar que a análise documental é uma técnica, ou mesmo uma fase da análise de conteúdo.

Para as finalidades dessa investigação, o corpus foi submetido a uma análise tanto qualitativa como também quantitativa, já que foram gerados dados estatísticos acerca da ocorrência dos aspectos observados e alguns pormenores das propostas de produção foram considerados em suas particularidades. 
Volume 14, número 1, ano 2018.

Para mostrar de que maneira os objetivos foram atingidos, este artigo está dividido da seguinte forma: inicialmente, expomos algumas considerações sobre os gêneros, o contexto de produção e a abordagem em espiral na discussão teórica. Em seguida, descrevemos a organização do LD para darmos sequência à análise quantitativa e qualitativa na qual trazemos exemplos ilustrativos e nosso posicionamento sobre os mesmos. Encerramos com as nossas considerações finais, trazendo as impressões finais que tivemos com o estudo, além das referências utilizadas.

\section{A TEORIA A SERVIÇO DE UM MELHOR ENTENDIMENTO SOBRE O OBJETO}

O trabalho com uma variedade de gêneros do discurso - que estejam de acordo com a escolaridade e a faixa etária dos alunos - leva a uma visão mais ampla do funcionamento social da linguagem e também à compreensão e apreciação desses gêneros fora da esfera escolar, na realidade na qual são produzidos e consumidos. Além disso, o contato com essa variedade leva à percepção de que os gêneros não constituem uma forma fixa, pois estão constantemente se renovando - com o surgimento de alguns e o desuso de outros - de acordo com as necessidades comunicativas e mudanças socioculturais e tecnológicas.

O estudo de gêneros distintos é uma forma de tornar o aluno apto a decodificar, compreender e interpretar textos materializados em gêneros, para que também possa se utilizar de sua capacidade textual-linguística e discursiva e produzi-los. A compreensão dos gêneros não possui uma finalidade meramente didática, mas também social, à medida que pode preparar o aluno para situações de uso concreto da língua fora da escola, considerando que somos seres sociais e sociáveis.

Segundo Schneuwly \& Dolz (2010), o trabalho com os gêneros na escola assume três vieses diferentes: (1) o gênero é desassociado de sua função comunicativa e passa a ser tratado como uma forma linguística - estereotipada e canônica - a ser dominada; (2) a escola é considerada um ambiente de comunicação autêntico, portanto os gêneros trabalhados não fazem referência à realidade exterior a ela; (3) os gêneros são trabalhados na escola tais quais 
Volume 14, número 1, ano 2018.

são encontrados nas práticas de linguagem, ou seja, não é feita distinção entre o que é interno e externo à escola.

Essa terceira maneira de abordar o gênero na escola implica que ele é uma forma de comunicação, um modelo comum e estável, indissociável das práticas de linguagem. Na escola, o gênero deixa de ser apenas um elemento para a interação e se torna um objeto de ensino-aprendizagem. Para Schneuwly \& Dolz (2010, p. 71), “[...] é o gênero que é utilizado como meio de articulação entre as práticas sociais e os objetos escolares, mais particularmente, no domínio do ensino da produção de textos orais e escritos".

A importância de se trabalhar com os gêneros está intimamente relacionada à importância de se abordar o contexto de produção dos textos escritos. Quando a escrita é feita apenas com um fim didático, apenas como tarefa a ser cumprida, a atividade pode ser encarada como algo desprovido de finalidade e sentido, como "uma espécie de protocolo curricular, deixando de oferecer ao aluno a oportunidade de perceber a complexidade que envolve o ato da escrita" (DA SILVA, 2008, p. 36). Nesse sentido, é crucial a clara explicitação do locutor, interlocutor, gênero, suporte e contexto de circulação do texto para um bom rendimento e aprendizado efetivo. Afinal, "a ideia de trabalhar com os gêneros na escola surgiu da necessidade de trazermos o contexto, ou seja, a situação de produção e recepção daquele texto, para a sala de aula. Quem escreve precisa saber para quem está escrevendo, o que quer dizer e com que objetivo está escrevendo" (COSCARELLI, 2007, p. $4)$.

Para que o conhecimento acerca dos diversos gêneros leve à formação de um bom produtor de textos, é indispensável que as propostas de produção de textos escritos estejam vinculadas às condições de produção e recepção do texto, pois um gênero não se constitui apenas pelo seu conteúdo temático, estrutura formal - ressaltando a flexibilidade dessa - e estilo linguístico, mas também pela sua função comunicativa (BAKHTIN, 1979). Cada gênero se presta a um papel dentro de uma situação de interação social e os fatores internos e externos a esta situação serão determinantes da forma como esse gênero será produzido e apresentado, de sua função comunicativa. Essa função, ao ser apreendida, permite a melhor identificação de quais elementos se utilizar para a produção de determinado texto. Segundo Geraldi (2013), é imprescindível saber para quem se escreve, sobre o que se escreve, por que 
Volume 14, número 1, ano 2018.

se escreve e onde o texto irá circular, caso contrário os alunos receberão uma formação que permitirá apenas a classificação de textos em gêneros, sem perceber a sua finalidade e sem apreender sentidos.

Os elementos mencionados acima como pertencentes ao gênero, de acordo com Bakhtin (1979), refletem a especificidade do âmbito de comunicação na qual se dá a produção e recepção do enunciado. O conteúdo temático consiste no tópico do enunciado e a estrutura formal equivale à organização composicional do mesmo. Já o estilo linguístico é a utilização dos recursos da língua - sejam eles lexicais ou gramaticais - que podem refletir a individualidade do produtor do enunciado caso o gênero permita, como é o caso dos gêneros artístico-literários. Nesse sentido, há uma diferenciação entre estilo do gênero e estilo do autor, mas ambos ainda se relacionam para formar um enunciado, pois "já que o gênero é uma forma típica do enunciado, no gênero a palavra incorpora esta tipicidade" (SIGNOR, 2008, p. 2). Estilo, tema e estrutura composicional estão indissociavelmente vinculados e, considerando-se que as esferas de atividade humana são variadas, esses elementos estão sujeitos a inúmeras variações, daí vem a ideia de que os gêneros são tipos relativamente estáveis de enunciados.

Aliado à diversidade dos gêneros do discurso na esfera escolar, torna-se importante a abordagem em espiral - que depende das restrições do sistema de ensino e do sistema educativo -, ou seja, a decomposição das atividades comunicativas que os alunos ainda não estão aptos a realizar de forma autônoma; o estabelecimento de uma sequência didática que permite um ensino sistemático e uma aprendizagem passo a passo (DOLZ e SCHNEUWLY, 2010).

A abordagem em espiral nos $\mathrm{LD}$, não só no de Português, permite o enfoque gradativo dado aos gêneros, ou aos conteúdos, que devem ser estudados, com níveis de complexidade e aprofundamento cada vez maiores ao longo dos anos escolares. O intuito é o de, ao mesmo tempo, fragmentar e fazer inteira a aprendizagem dos gêneros - o que consiste num ensino progressista -, levando os alunos ao entendimento paulatino e efetivo dos mesmos.

Sendo assim, pressupomos que, para tornar efetivo o ensino-aprendizagem da produção de textos escritos, é fundamental que os alunos tenham contato com uma variedade 
Volume 14, número 1, ano 2018.

de gêneros do discurso, advindos das mais diversas situações comunicativas, dotados de diferentes funções sociais e integrantes de variadas esferas de atividade humana, bem como que esses gêneros sejam selecionados de modo que o conteúdo a ser estudado retome um aprendizado anterior, porém com uma nova abordagem e nível de dificuldade mais avançado, com o objetivo de aperfeiçoar a prática da linguagem.

\section{EIS QUE SURGEM OS DADOS E AS CONSIDERAÇÕES A SEU RESPEITO}

\subsection{Descrição do corpus}

A coleção 'Português Linguagens', de William Roberto Cereja e Thereza Cochar Magalhães, $6^{\circ}$ a $9^{\circ}$ ano, Atual Editora, inicia-se com uma breve apresentação dedicada aos estudantes, ressaltando a importância do ser curioso, do buscar aprender, do trocar ideias e do interesse em transitar entre as linguagens. Em seguida, somos direcionados ao sumário da obra, que, ao todo, é dividida em quatro unidades, com três capítulos cada.

A abertura de cada unidade é constituída de textos não verbais e verbais que introduzem o aluno ao tema que será abordado durante a mesma. Há também sugestões de livros, sites, vídeos e músicas que podem ser consultados pelos alunos. Dos três capítulos de cada unidade, dois são iniciados com textos verbais. Há cinco divisões dentro dos capítulos, que não estão, necessariamente, presentes em todos eles: Estudo do texto; Produção de Texto, Para escrever com adequação/coerência/coesão/expressividade; A língua em foco e De olho na escrita.

No início dos capítulos, o aluno é apresentado ao Estudo do texto, o qual é dedicado à leitura e a atividades de leitura. Nessa seção - que tem como objetivo, entre outros, despertar o prazer de ler -, o aluno poderá desenvolver as suas habilidades de compreensão e interpretação da linguagem, além de trocar ideias com os colegas e professores sobre o tema do capítulo. Em seguida, em Produção de texto, o aluno é levado a produzir um texto de um gênero que se relaciona com o tema da unidade. A seção Para escrever com adequação/coerência/coesão/expressividade visa a orientar a produção do aluno quanto à textualidade e ao discurso.

Por fim, A língua em foco propõe um trabalho linguístico gramatical e De olho na escrita traz atividades referentes à ortografia e acentuação. De acordo com os autores (p. 
Volume 14, número 1, ano 2018.

8, Manual do Professor - MP), o enfoque do estudo não é apenas a gramática normativa e descritiva, mas também a gramática de uso e reflexiva.

No final de cada unidade há o capítulo Intervalo, que retoma o tema trabalhado e apresenta um conjunto de atividades propostas pelos autores para que os professores realizem com seus alunos, como confecção de jornais, realização de feiras, seminários, teatros, entre outros. O objetivo é expandir o conhecimento adquirido em sala de aula e torná-lo mais real aos olhos do estudante.

Em relação ao MP, todas as seções são satisfatoriamente explicadas e teorizadas. Nesta parte, explicam-se os papéis do professor e da escola ao trabalharem com a coleção. Na parte 'Outros Procedimentos Didáticos' o professor encontra um bom guia de como trabalhar a produção de textos, com indicação de caminhos para que não haja manifestações de desânimo nos alunos.

O guia do Programa Nacional do Livro Didático (PNLD) é favorável ao LD em questão, pois afirma que, especificamente em relação às propostas de produção de texto escrito, nosso foco neste artigo, "há indicação sobre o público alvo, uso adequado da linguagem, características próprias do gênero a ser escrito, importância da releitura e da reescrita” (p. 114), com a ressalva de que a interferência do professor é essencial ao se utilizar o LD.

\subsection{Procedimentos para a geração de dados}

A geração de dados e posterior análise e, consequentemente, o alcance dos objetivos pretendidos, se deu da seguinte forma: as condições de produção do texto - locutor, interlocutor, gênero, suporte e contexto de circulação - foram consideradas como categorias e, após apurada a sua frequência de aparição, os dados foram convertidos em gráficos para depois proceder-se à análise qualitativa.

Para averiguar se há ou não variedade de gêneros propostos para produção de texto escrito, inicialmente, os mesmos foram apresentados em um quadro. Em seguida, foi feita uma comparação da quantidade total de propostas de produção de texto com a quantidade de gêneros encontrada. Essas quantidades foram expostas em números totais e 
Volume 14, número 1, ano 2018.

percentuais. Com isso, foi possível estabelecer um paralelo, que levou à percepção da suficiência ou não dos gêneros trabalhados pelo LD.

Essa metodologia também permitiu a constatação da (não) repetição de um mesmo gênero durante os quatro anos do Ensino Fundamental 2. Nos casos em que mais de uma proposta solicitou a produção de texto de um mesmo gênero, observamos se isso favoreceu (ou não) a abordagem da progressão em espiral.

$\mathrm{Na}$ análise qualitativa, foram apresentadas atividades retiradas do LD, as quais serviram de ilustração daquilo que estará sob análise.

\subsection{Dados quantitativos e qualitativos}

No gráfico na sequência, mostramos a porcentagem de aparição de cada integrante do contexto de produção dos textos propostos para escrita, nos quatro volumes da coleção. Em seguida, trazemos nossas impressões analíticas sobre esses dados a partir de uma atividade ilustrativa.

Gráfico 1: Contexto de produção $-6^{\circ}$ a $9^{\circ}$ ano

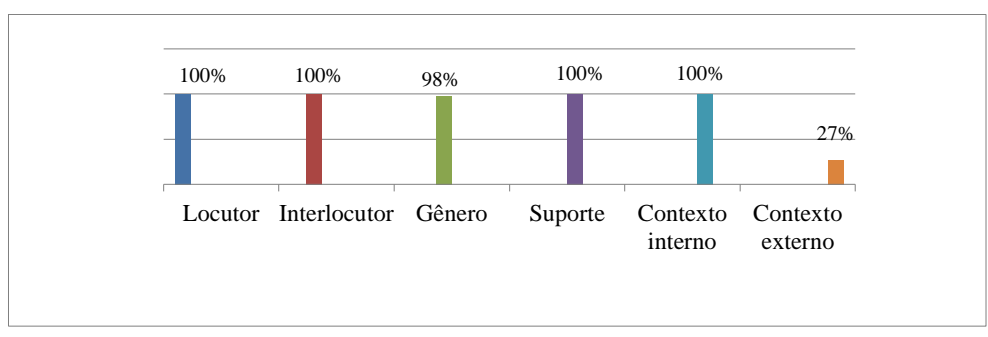

Fonte: elaboração própria

Dentre os integrantes do contexto de produção, optamos por analisar aqueles que apresentaram menos ocorrência ao longo da coleção - indicação do gênero e contexto externo - já que os demais tiveram ocorrência de $100 \%$.

A atividade ilustrativa que contempla esses critérios foi retirada do LD do $7^{\circ}$ ano, Unidade 3, Capítulo 1, que visa a trabalhar o texto campanha comunitária. Inicialmente, o LD reproduz uma campanha (p. 123) com o propósito de combater o preconceito contra a Síndrome de talidomida (deformações físicas que podem ter sido causadas por uso de medicamentos durante a gestação). Em seguida, aparecem 12 questões, trabalhando com as 
Volume 14, número 1, ano 2018.

finalidades de uma campanha comunitária e com a interpretação e aspectos linguísticos do texto. Por fim, o LD apresenta duas propostas de produção escrita que farão parte de uma campanha na escola, com orientações e sugestões de temas, mas sem a indicação de qual gênero deverá ser produzido e também sem contexto externo. Ressaltamos que consideramos como contexto externo aquele que ultrapassa os limites do ambiente escolar.

\section{Quadro 1. Atividade ilustrativa - gênero e contexto externo}

Há, a seguir, duas propostas de produção de textos de campanha comunitária. Os textos produzidos pela classe serão expostos na feira Solidariedade e respeito, que será realizada no capítulo intervalo desta unidade. Portanto, eles serão lidos pelos convidados para o evento: colegas de sua classe e de outras, professores e funcionários da escola, seus amigos e familiares.

$[\ldots]$

Fonte: LDP, $7^{\circ}$ ano - Unidade 3 - Capítulo 1 - p. 125

Segundo Antunes (2003, p. 115), é importante o trabalho com a escrita contextualizada, que é "a escrita que faz sentido porque fala de nós e de nosso mundo". Fazse necessário, então, que o educador transcenda ao que é sugerido pelo LD adotado, buscando em sua formação referências que norteiem o como trabalhar, ponderando os diálogos que o texto estabelece com o mundo para exercitar essa escrita. Ou seja, além de saber a que gênero um texto pertence e saber identificar as características desse gênero, faz-se necessário, ainda, que os estudantes saibam a finalidade do texto, identificando, também, o contexto em que ele está inserido.

Como já dito, de acordo com Geraldi (2013), é imprescindível saber para quem se escreve, sobre o que se escreve, por que se escreve e onde o texto irá circular. Caso contrário, os alunos receberão uma formação que permitirá apenas a classificação de textos em gêneros, sem perceber a sua finalidade e apreender sentidos. A atividade ilustrativa do $7^{\circ}$ ano não traz especificação de gênero e nem contexto externo - aquele que vai além do ambiente escolar -, mas é eficaz ao mostrar para o aluno a finalidade do texto que será produzido e a sua função social, que é a de alertar a comunidade para a seriedade de certos problemas sociais - como trabalho infantil, reciclagem do lixo, valorização dos idosos, entre outros - e combatê-los. Consideramos que, ao tratar de questões que estão próximas à realidade vivida pelos alunos, o 
Volume 14, número 1, ano 2018.

LD está contribuindo para que eles atribuam sentido à produção de texto e não a encarem apenas como tarefa escolar a ser cumprida.

Na sequência, apresentamos uma tabela que traz todos os gêneros trabalhados pelo LD durante os quatro anos e indicamos se houve variedade ou não, com base na comparação da quantidade total de propostas de produção de texto com a quantidade de gêneros encontrada. Também discorremos qualitativamente sobre esses dados a partir de uma atividade. Não apresentamos mais de uma vez a repetição do mesmo gênero.

Quadro 2: Variedade de gêneros

\begin{tabular}{|c|c|c|c|}
\hline $6^{\circ}$ ano & $7^{\circ}$ ano & $8^{\circ}$ ano & $9^{\circ}$ ano \\
\hline Conto maravilhoso & Mito & Crítica & Editorial \\
\hline História em Quadrinho & Narrativa escolar & Crônica & Conto \\
\hline Relato pessoal & História em Quadrinho & Crônica argumentativa & $\begin{array}{c}\text { Dissertação } \\
\text { argumentativa }\end{array}$ \\
\hline Carta pessoal & Poema & Anúncio publicitário & \multirow{6}{*}{ Reportagem } \\
\hline E-mail & $\mathrm{NA}^{7}$ & Carta de leitor & \\
\hline Diário & Notícia & Carta denúncia & \\
\hline Blog & \multirow{3}{*}{ Entrevista } & Divulgação científica & \\
\hline Texto de opinião & & Texto teatral & \\
\hline Cartaz & & & \\
\hline
\end{tabular}

Fonte: LDP

Constatamos que, no $6^{\circ}$ ano, foram apresentadas treze (13) propostas de produção de texto escrito. Dentre elas, nove (9) gêneros foram trabalhados, o que equivale a sessenta e nove por cento (69\%) do número total. Já no $7^{\circ}$ ano, foram apresentadas dez (10) propostas e trabalhados seis (6) gêneros, o que corresponde a sessenta por cento $(60 \%)$ do número total. No $8^{\circ}$ ano, foram apresentadas onze (11) propostas e trabalhados oito (8) gêneros, correspondendo a setenta e três por cento $(73 \%)$. Por fim, no $9^{\circ}$ ano foram apresentadas dez (10) propostas e trabalhados quatro (4) gêneros, correspondendo a quarenta por cento (40\%). No total, considerando-se os quatro (4) volumes, houve quarenta e quatro (44) propostas de produção de texto escrito e vinte e sete (27) gêneros diferentes, equivalendo a setenta e nove por cento $(79 \%)$ do valor total.

\footnotetext{
${ }^{7}$ NA quer dizer que não foi possível identificar o gênero proposto
} 
Volume 14, número 1, ano 2018.

A positividade de haver um maior número de gêneros apresentados ao aluno tende a favorecer a apropriação de uma variedade maior de letramentos, considerando que quanto maior a variedade de gêneros produzidos, maiores as chances de o aluno ter domínio sobre um número maior de letramentos. Consideramos que houve variedade de gêneros propostos para produção de texto escrito, exceto no $9^{\circ}$ ano, como apresentado há pouco. O que houve nesta série foi a repetição de um mesmo gênero mais de uma vez.

Um aspecto que notamos em relação a como os gêneros são apresentados ao aluno ao longo das séries é que é facilmente perceptível a opção propedêutica de organização dos referidos. Isso significa que começa-se por aqueles considerados mais fáceis (narrativos) e vai-se passando para os considerados mais difíceis (argumentativos). Dolz, Noverraz e Schneuwly ([2001]2010, p. 120) nos dizem que "não é porque se domina o processo de escrita de um texto narrativo que se domina o processo de escrita de um texto explicativo". Nesse sentido, a organização da progressão escolar feita de forma propedêutica poucos benefícios traz ao aluno, já que, ainda segundo os autores há pouco mencionados, "cada gênero necessita de um ensino adaptado, pois apresenta características distintas: os tempos verbais não são os mesmos quando se relata uma experiência vivida ou quando se escreve instruções para a fabricação de um objeto" (DOLZ, NOVERRAZ e SCHNEUWLY, 2010, p. 120).

Dolz e Schneuwly (2010) consideram que no momento de se pensar na organização dos gêneros que serão ensinados ao aluno deve-se priorizar aqueles da comunicação pública formal ao invés daqueles da vida privada cotidiana. Nesse sentido, entendemos que a coleção apresentou uma abordagem significativa para o aluno, uma vez que propõe a produção de gêneros formais, como a notícia, o anúncio publicitário e o texto de divulgação científica, por exemplo.

Para ilustrar a existência de variedade de gêneros propostos para produção de texto escrito apresentamos uma atividade do livro do $9^{\circ}$ ano, no qual menos ocorreu essa diversificação de gêneros. A atividade ilustrativa aparece na Unidade 4, Capítulo 1, que visa a trabalhar o texto dissertativo-argumentativo e o conceito de informatividade.

Para trabalhar esse conceito, o LD traz um (01) cartum (p. 203), seguido de duas (02) questões, que mostram como os textos com os quais nos deparamos exigem conhecimentos prévios do leitor; e um (01) texto sobre violência social, seguido de seis (06) 
Volume 14, número 1, ano 2018.

questões, que levam o aluno a analisar o grau de informatividade textual. Por fim, são apresentados quatro (04) textos sobre clonagem, seguidos de seis (06) instruções sobre como escrever um texto dissertativo-argumentativo. É pedido ao aluno que se posicione sobre o assunto e discorra sobre ele.

\section{Quadro 6. Atividade ilustrativa - variedade de gêneros}

Entre nessa discussão: você é a favor da clonagem? Se não, por quê? Se sim, que tipo de clonagem: de animais, de células-tronco para tratar de doenças de seres humanos, de alimentos (os transgênicos)?

Delimite o tema - isto é, escolha o tipo de clonagem que vai abordar -, tome uma posição sobre ele e oriente-se pelas instruções a seguir.

a) Pense no leitor: o texto ficará exposto no mural que será montado no projeto do capítulo Intervalo desta unidade e será lido por colegas de outras classes, professores e funcionários da escola, familiares e amigos.

\section{$[\ldots]$}

Fonte: LDP, $9^{\circ}$ ano - Unidade 4 - Capítulo 1 - p. 209

O ensino de Língua Portuguesa tem como objetivo ampliar as possibilidades do uso da linguagem e, por este motivo, faz-se necessário o trabalho com textos ancorados em gêneros do discurso, pois são estes que efetivam a aprendizagem da comunicação verbal e proporcionam a participação do indivíduo na construção do sentido do texto. A esse respeito, Dolz e Schneuwly (2010, p. 174) nos dizem que "os gêneros constituem a referência essencial para se abordar a infinita variedade das práticas de linguagem e o meio de se tratar a heterogeneidade constitutiva das unidades textuais". Dessa forma, o trabalho com os gêneros em classe traz inúmeros benefícios à aprendizagem do aluno. Assim, é importante que esses gêneros não sejam trabalhados isoladamente, com atividades de decodificação e memorização, mas encaminhados para uma reflexão dos sentidos, levando em conta a situação na qual são lidos e o contexto em que foram escritos.

Segundo Coscarelli (2007, p. 83), não precisamos conhecer todos os gêneros do discurso, pois essa atividade é até mesmo impossível dada à quantidade de gêneros existentes. É Bakhtin (1979, p. 303) quem nos diz que "se não existissem os gêneros do discurso e se não os dominássemos, se tivéssemos de criá-los pela primeira vez no processo da fala, se tivéssemos de construir cada um de nossos enunciados, a comunicação verbal seria quase impossível". 
Volume 14, número 1, ano 2018.

Assim sendo, a maioria das pessoas não precisa saber escrever bula de remédio, mas a maioria delas precisa saber ler bulas. Em vista disso, é importante que o professor, em seu papel de mediador, ofereça esses caminhos para o conhecimento do maior número possível de gêneros, levando o aluno a encontrar e compreender as informações a respeito deles quando necessário. Isso vai depender muito da comunidade de práticas e das situações de comunicação que são mais recorrentes naquele ambiente.

Apesar do LD do $9^{\circ}$ ano não trabalhar com gêneros distintos, esse trabalho é feito nos demais volumes, como demonstramos no Quadro 2, e a atividade ilustrativa que acabamos de apresentar é bem desenvolvida e contributiva para o aperfeiçoamento das habilidades linguísticas do aluno. Dentro da atividade escolhida, percebemos uma quantidade notável de material para leitura, textos que, se bem explorados pelo professor mediador, podem orientar o aluno na hora da produção e ajudá-lo a desenvolver e planejar suas ideias. Essa leitura prévia para a posterior formulação de ideias é até mesmo mais importante do que a competência para a escrita, porque "ter o que dizer é, portanto, uma condição prévia para o êxito da atividade de escrever. Não há conhecimento linguístico (lexical ou gramatical) que supra a deficiência do 'não ter o que dizer"' (ANTUNES, 2003, p. 45).

Em relação à abordagem em espiral, o quadro na sequência mostra as vezes em que um mesmo gênero foi retomado na mesma série ou não. Na sequência, mostramos se houve ou não abordagem em espiral, esclarecendo como ela ocorre através de três atividades do LD.

Quadro 7: Abordagem em espiral $-6^{\circ}$ a $9^{\circ}$ ano ${ }^{8}$

\begin{tabular}{|c|c|c|}
\hline Gênero & Ano & Ocorrências \\
\hline \multirow{5}{*}{ Conto } & $6^{\circ}$ & \\
\hline & $6^{\circ}$ & \\
\hline & $9^{\circ}$ & $\mathrm{X}$ \\
\hline & $9^{\circ}$ & $X$ \\
\hline & $9^{\circ}$ & \\
\hline \multirow{4}{*}{ História em quadrinho } & $6^{\circ}$ & \\
\hline & $6^{\circ}$ & $X$ \\
\hline & $6^{\circ}$ & $X$ \\
\hline & $7^{\circ}$ & \\
\hline
\end{tabular}

\footnotetext{
${ }^{8} \mathrm{O}$ ' $\mathrm{x}$ ' representa o gênero que foi trabalhado novamente pela coleção com abordagem em espiral. Os espaços
} não assinalados significam que houve mais de uma vez trabalho com o gênero, mas sem abordagem em espiral. 
Volume 14, número 1, ano 2018.

\begin{tabular}{|c|c|c|}
\hline \multirow{3}{*}{ Carta } & $6^{\circ}$ & \\
\hline & $8^{\circ}$ & $\mathrm{X}$ \\
\hline & $8^{\circ}$ & $X$ \\
\hline \multirow[t]{2}{*}{ Reportagem } & $9^{\circ}$ & \\
\hline & $9^{\circ}$ & \\
\hline \multirow{3}{*}{ Poema } & $7^{\circ}$ & \\
\hline & $7^{\circ}$ & \\
\hline & $7^{\circ}$ & $\mathrm{X}$ \\
\hline \multirow{3}{*}{ Crônica } & $8^{\circ}$ & \\
\hline & $8^{\circ}$ & $\mathrm{X}$ \\
\hline & $8^{\circ}$ & $X$ \\
\hline \multirow[t]{2}{*}{ Divulgação científica } & $8^{\circ}$ & \\
\hline & $8^{\circ}$ & \\
\hline
\end{tabular}

Fonte: elaboração própria

Constatamos que dos vinte e sete (27) diferentes gêneros que são abordados no LD, sete (07) aparecem mais de uma vez. A abordagem em espiral poderia ter ocorrido em quinze (15) propostas $^{9}$, mas só ocorreu em nove (09), o que corresponde a sessenta por cento (60\%) das ocorrências.

Para Dolz e Schneuwly (2010), o princípio da abordagem em espiral está ligado ao fato de que um mesmo gênero pode ser abordado diversas vezes ao longo da escolaridade, com graus crescentes de aprofundamento. Esses graus de aprofundamento dizem respeito, por exemplo, ao trabalho com novos elementos pertencentes ao gênero que não foram trabalhados anteriormente. A intenção disso é fazer com que o aluno se aproprie cada vez mais de um número maior de operações ligadas ao funcionamento da linguagem.

Para ilustrar a existência da abordagem em espiral no tratamento dado aos gêneros do discurso propostos para produção, apresentamos três propostas em que o gênero pedido é a carta. A primeira delas aparece no LD do $6^{\circ}$ ano e visa a trabalhar a carta pessoal. O LD traz uma carta de um filho para o pai (p. 144), seguida de seis questões que ressaltam o assunto e a estrutura de uma carta pessoal, o que é um encaminhamento para que o aluno se aproprie da forma composicional do gênero em questão.

\footnotetext{
${ }^{9}$ Desconsideramos a primeira proposta na qual esses gêneros aparecem, pois não é possível haver abordagem em espiral sem uma proposta antecendente. Dessa forma, as vinte e sete (27) propostas são reduzidas para quinze (15).
} 
Volume 14, número 1, ano 2018.

Em seguida, é pedido ao aluno que redija uma carta pessoal seguindo seis instruções.

\section{Quadro 8: Atividade ilustrativa - abordagem em espiral - 1 $^{\text {a }}$ atividade}

Escreva uma carta, comentando um assunto e convidando seu destinatário a dar uma resposta.

Siga estas instruções:

a) Peça ao professor o nome e o endereço completos de seu correspondente ou escolha um amigo de outro ano com quem possa se corresponder.

b) Escolha um dos assuntos sugeridos a seguir ou pense em outro de sua preferência:

- Livros e filmes preferidos

- RPG e games

- Heróis de TV ou de histórias em quadrinhos

- Coleções

- Animais de estimação

- Esportes e campeonatos

- Viagens e passeios

c) Empregue uma variedade linguística de acordo com o interlocutor, isto é, adequada à idade dele e ao grau de intimidade existente entre vocês.

d) Ao terminar sua carta, avalie-a de acordo com as orientações do boxe Avalie sua carta pessoal passe-a a limpo, com bastante capricho, de preferência em um papel de carta especial. Se quiser, crie o "papel especial": pegue uma folha de caderno ou sulfite, branca ou colorida, e recorte-a no formato que achar interessante. Invente uma moldura e pinte-a com lápis de cor ou ilustre a carta com desenhos ou recortes.

e) Preencha o envelope com o nome e endereço completos do destinatário e do remetente. Cole o selo. Depois envie a carta, seguindo as orientações do professor, e aguarde a resposta.

f) Se gostar da experiência, continue se correspondendo com o colega.

\section{Avalie sua carta pessoal}

Leia sua carta e observe se nela constam local, data e vocativo; se há assunto, uma despedida amigável e assinatura. Embora as cartas pessoais sejam informais, verifique se a linguagem está adequada ao seu interlocutor e à situação. Quanto ao envelope, observe se os dados do destinatário e o remetente estão completos.

Fonte: LDP, $6^{\circ}$ ano - Unidade 3 - Capítulo 2 - p. 146

A segunda ocorrência do mesmo gênero aparece no LD do $8^{\circ}$ ano e visa a trabalhar a carta de leitor. O LD traz quatro cartas de leitor (p. 148), retiradas de jornais e revistas, seguidas de seis questões que trabalham com o seu conteúdo, a estrutura e a linguagem utilizada nesse tipo de carta, ressaltando a sua natureza argumentativa. Além de nortear o aluno acerca da forma composicional da carta (o que também foi feito na proposta do $6^{\circ}$ ano), ao dar enfoque à linguagem utilizada no gênero, o LD está orientando o aluno a se 
Volume 14, número 1, ano 2018.

atentar para o estilo do mesmo, sendo o estilo um dos três elementos pertencentes ao gênero segundo Bakhtin (1979).

Em seguida, é solicitado ao aluno que leia uma reportagem sobre "cyberbulling" e produza uma carta de leitor orientado por cinco instruções.

\section{Quadro 9: Atividade ilustrativa - abordagem em espiral $-2^{\mathrm{a}}$ atividade}

Reúna-se com seus colegas de grupo e escolham uma revista ou um jornal para ser lido. Pode ser um jornal do bairro, da cidade ou do Estado ou uma revista que trate de música, de esportes, de cinema, etc. Selecionem nesse veículo de comunicação uma matéria que seja interessante e que, segundo o ponto de vista de vocês, mereça comentários, quer positivos, quer negativos, ou ainda as duas coisas. Escrevam então uma carta à revista ou jornal, comentando a matéria.

Sigam estas instruções:

a) Anotem e discutam os aspectos da matéria merecedores de comentários, bem como os argumentos que vão fundamentar o ponto de vista de vocês - por que gostaram ou por que não gostaram, etc.

b) Redijam o texto atentos à estrutura desse tipo de carta. Deixem claro, desde o início, a data do jornal ou o número da revista em que foi publicada a matéria sobre a qual estão opinando. Identifiquem a matéria pelo título e/ou pelo nome do jornalista que a assina.

c) Opinem de forma firme mas educada, sempre com base em bons argumentos. Se estiverem fazendo uma crítica negativa, não deixem de elogiar alguns pontos positivos.

d) Tenham em vista o leitor da carta, que será primeiramente o jornalista ou o editor e, se ela for publicada, o leitor do jornal ou revista - criança, jovem ou adulto. Procurem adequar a linguagem ao perfil desses leitores.

e) Quando finalizaram a carta, revisem-na de acordo com o boxe Avalie sua carta de leitor. Depois leiam-na para outros grupos, de modo que toda a classe opine. Modifiquem o que for necessário, passem o texto a limpo em papel de carta e enviem-no à redação da revista ou jornal, tomando o cuidado de preencher corretamente o envelope. Se preferirem, e se tiverem o e-mail da revista ou do jornal, enviem a carta pela Internet. Depois acompanhem os números subsequentes da revista ou jornal, a fim de observar sua publicação.

\section{Avalie sua carta de leitor}

Observe se a carta apresenta: local e data, vocativo, corpo do texto (assunto), despedida e assinatura; uma opinião sobre a matéria publicada no jornal ou revista, uma reclamação ou uma reivindicação; argumentos que expliquem ou fundamentem os motivos da opinião, da reclamação ou da reivindicação; linguagem e tratamento de acordo com o perfil do(s) interlocutor(es) e com o gênero.

Fonte: LDP, $8^{\circ}$ ano - Unidade 3 - Capítulo 2 - p. 151

Por fim, a terceira ocorrência do mesmo gênero aparece também no LD do $8^{\circ}$ ano e visa a trabalhar a carta-denúncia. O LD explica (p. 167), brevemente, que a função desse 
Volume 14, número 1, ano 2018.

gênero é reclamar ou solicitar algo a autoridades, empresas ou imprensa. Em seguida, traz uma carta como exemplo e sete questões que trabalham a sua estrutura, tema, finalidade e linguagem. Assim como nas propostas anteriores, o LD está encaminhando o aluno para se apropriar dos elementos do gênero: forma composicional e estilo.

É solicitado ao aluno que redija uma carta-denúncia com base em três instruções.

\title{
Quadro 10: Atividade ilustrativa - abordagem em espiral $-3^{a}$ atividade
}

\begin{abstract}
Reúna-se com seus colegas de grupo e, juntos, façam uma pesquisa no bairro em que moram para identificar problemas que possam ser solucionados pela administração pública sem exigir grandes investimentos: buracos no asfalto, mato em terrenos baldios, vazamentos de água, esgoto entupido, excesso de barulho à noite, cães vadios nas ruas, etc. Escrevam uma carta, que poderá ser endereçada ao jornal da região.

Sigam estas instruções:

a) Discutam o tipo de denúncia que pretendem fazer e a quem será dirigida a carta.

b) Redijam a carta observando a estrutura conveniente, as formas de tratamento adequadas, a apresentação do problema, a reivindicação principal e os argumentos que fundamentam a denúncia.

c) Revisem o texto de acordo com as orientações do boxe Avalie sua carta-denúncia, corrigindo o que for necessário. Depois passem o texto a limpo, leiam-no para a classe e discutam com o professor a melhor forma de divulgar a carta-denúncia que produziram.
\end{abstract}

\section{Avalie sua carta-denúncia}

Observe se a carta apresenta: local e data, vocativo, corpo do texto (assunto), despedida e assinatura; uma denúncia; argumentos que expliquem ou fundamentem os motivos da denúncia; linguagem e tratamento de acordo com o perfil do(s) interlocutor(es) e com o gênero.

Fonte: LDP, $8^{\circ}$ ano - Capítulo 3 - Unidade 3 - p. 168

Conforme já dito, a abordagem em espiral consiste na distribuição dos conteúdos a serem estudados com a intenção de tornar a aprendizagem progressiva e gradual. Dessa forma, um gênero não é trabalhado em sala de aula apenas em um ano ou em uma unidade do LDP, mas sim múltiplas vezes, cada uma delas agregando um conhecimento novo e aprofundando o nível de complexidade. Segundo Dolz \& Schneuwly ([1996]2010), para assegurar essa continuidade de aprendizagem, deve-se ter uma visão geral dos objetos de ensino a serem abordados para então decompô-los e definir certo número de conteúdos ou elementos chave.

Nas atividades ilustrativas escolhidas, o gênero em estudo é a carta, sendo que é trabalhada inicialmente a carta pessoal, seguida da carta de leitor e, por fim, da carta- 
Volume 14, número 1, ano 2018.

denúncia. A estrutura formal - que consiste na organização composicional do texto - de todas elas é parecida, sendo constituída, em linhas gerais, de local e data, vocativo, corpo do texto (assunto), despedida e assinatura. A incorporação de novos elementos não estudados anteriormente, ou seja, a presença da abordagem em espiral, aparece com mais veemência nos aspectos estilísticos e temáticos.

No gênero carta, é comum que ocorra o que chamamos de heterogeneidade tipológica, ou seja, uma miscelânea de tipos de texto (descrição, injunção, exposição, narração e argumentação) em um mesmo gênero (DA SILVA, 2010). Entretanto, em cada um dos gêneros abordados pelo LD há a predominância de um aspecto tipológico. Na carta pessoal, o enfoque é narrativo, já que o remetente conta histórias privadas e experiências vividas, situando-as em um determinado tempo. Em relação ao estilo, ele é mais íntimo e menos formal. Esta carta se constitui naquilo que Bakhtin (1979) denomina como sendo um gênero primário, menos complexo. Na carta de leitor, o enfoque é argumentativo, pois, como afirma o LD do $8^{\circ}$ ano (p. 149), sua função é permitir aos leitores "reclamar, solicitar, discordar, elogiar, etc" e, obviamente, são necessários argumentos para fundamentar essas reclamações, solicitações, elogios. A respeito do estilo, ele já é menos íntimo e um pouco mais formal que a carta pessoal. A carta de leitor se constitui naquilo que Bakhtin (1979) denomina como sendo um gênero secundário, mais complexo. Já a carta-denúncia, apesar de também apresentar uma natureza argumentativa como a carta de leitor, tem um caráter expositivo muito grande, já que necessita apresentar fatos e irregularidades e expô-los publicamente. $\mathrm{O}$ estilo aqui precisa ser altamente formal, mesmo porque, em geral, é dirigida a uma autoridade. Esta carta, da mesma forma que a carta de leitor, se constitui naquilo que Bakhtin (1979) denomina como sendo um gênero secundário, ainda mais complexo que a anterior.

Ainda abordando o estilo linguístico das cartas, notamos que o LDP orienta o aluno na carta pessoal a usar uma variedade linguística de acordo com o interlocutor, sua idade e o grau de intimidade que tem com ele. Nas orientações para que avalie sua própria carta ressalta-se a questão do interlocutor novamente, considerando que cartas pessoais são informais. Aqui percebemos o que nos diz Bakhtin (1979, p. 322) ao afirmar que

Enquanto falo, sempre levo em conta o fundo perceptivo sobre o qual minha fala será recebida pelo destinatário: o grau de informação que ele tem da 
Volume 14, número 1, ano 2018.

situação, seus conhecimentos especializados na área de determinada comunicação cultural, suas opiniões e suas convicções, seus preconceitos (de meu ponto de vista), suas simpatias e antipatias, etc [...].

Para o autor, esses fatores são determinantes para que os recursos linguísticos sejam escolhidos e o LDP orientou adequadamente o aluno quanto a isso.

Tratamento semelhante acontece em relação às outras duas cartas apresentadas. $\mathrm{Na}$ carta de leitor, o aluno é orientado a também pensar no leitor (jornalista ou editor do jornal ou revista para onde a carta será encaminhada), adequando sua linguagem (estilo) ao perfil desse leitor. Já na carta denúncia, os alunos deverão observar as formas de tratamento adequadas ao destinatário. Citando Bakhtin (1979, p. 322) mais uma vez, trazemos à tona as considerações do filósofo da linguagem quando diz que "nas esferas da vida cotidiana ou da vida oficial, a situação social, a posição e a importância do destinatário repercutem na comunicação verbal de um modo todo especial". Assim, quando o LDP chama a atenção do aluno para as formas de tratamento em relação ao interlocutor colabora com a sua percepção de que é o destinatário quem induz o locutor a usar este ou aquele tratamento estilístico, não se tratando, pois, de livre escolha do locutor. Ainda sobre isso, Bakhtin (1979, p. 323) afirma que

A estrutura da sociedade em classes introduz nos gêneros do discurso e nos estilos uma extraordinária diferenciação que se opera de acordo com o título, a posição, a categoria, a importância conferida pela fortuna privada ou pela notoriedade pública, pela idade do destinatário e, de modo correlato, de acordo com a situação do próprio locutor (ou escritor).

Assim, nota-se que o LDP foi tornando mais complexo o tratamento estilístico a ser dado à carta à medida que as propostas foram sendo apresentadas. Na carta pessoal, ressalta que o estilo linguístico deve ser adequado à idade dele e ao grau de intimidade existente entre o aluno e seu interlocutor (que pode ser um amigo). Já na carta de leitor, não existe a orientação quanto ao grau de intimidade, já que o interlocutor é alguém distante. O que o aluno deve observar é o uso linguístico adequado a este interlocutor. Em relação à carta denúncia, chama-se a atenção para as formas de tratamento adequadas, diferentemente do que foi feito antes uma vez que não se chamou a atenção do aluno para formas de tratamento, mas unicamente para o interlocutor. 
Volume 14, número 1, ano 2018.

Percebe-se a abordagem em espiral nas considerações do LDP também quanto à forma composicional. $\mathrm{Na}$ carta pessoal, diz-se para que o aluno use um papel de carta especial, podendo, inclusive, criar esse papel, colocando moldura, pintando com lápis de cor ou ilustrando com desenhos, de forma que nada é para ser formal. Na carta de leitor, a orientação é apenas para que o aluno passe o texto a limpo em papel de carta, sem especificar que o papel deve ser colorido, com moldura ou ilustrado com figuras do seu gosto como foi feito na carta pessoal. Na carta de leitor, ainda, chama-se a atenção do aluno para a estrutura da carta, quando se diz para redigir atento à estrutura desse tipo de carta (embora não apareçam orientações quanto a isso). Também é chamada a atenção do aluno para o fato de que, desde o início da carta, deve aparecer a data do jornal ou o número da revista em que foi publicada a matéria sobre a qual estão opinando. Já na carta denúncia, a única orientação é para que o aluno passe o texto a limpo, não indicando sequer o tipo de papel que deve ser usado.

A abordagem em espiral está presente, também, em relação ao tema. Na carta pessoal, fica claro, desde o início, que se trata de uma abordagem menos complexa, um gênero primário, como dissemos, já que os tópicos a serem escolhidos são da esfera íntima, como animais de estimação, viagens e passeios. Na carta de leitor, os alunos deverão selecionar uma matéria interessante do ponto de vista deles em relação a pontos positivos ou negativos. $\mathrm{O}$ aspecto da progressão aqui aparece quando, nesta carta, ocorre a orientação para a escolha de argumentos que fundamentarão o ponto de vista dos alunos, o que não ocorreu em relação à carta pessoal, considerando que seus temas não direcionam para a necessidade de defesa de ponto de vista explicitamente. Já na carta denúncia, de cunho eminentemente argumentativo, também é chamada a atenção para o aspecto argumentativo, porém de forma mais elaborada, indicando, até, a estrutura do texto argumentativo, o qual deve ter apresentação do problema, reivindicação principal e argumentos que fundamentam a denúncia a ser feita.

\section{CONSIDERAÇÕES FINAIS}

Neste estudo, tivemos como objetivos analisar se as propostas de produção de texto escrito apresentadas pelo livro didático de Português (LDP) 'Português Linguagens' 
Volume 14, número 1, ano 2018.

trabalham as condições de produção do texto (locutor, interlocutor, gênero, suporte, contexto de circulação); verificar a (in)existência de variedade de gêneros do discurso propostos para produção de textos escritos; e averiguar a (in)existência da abordagem em espiral no tratamento dado aos gêneros do discurso propostos para produção conforme a perspectiva bakhtiniana.

Ao chegar ao final das análises, obtivemos alguns resultados que contribuíram para a percepção de pontos positivos e dos que ainda requerem ajustes dentro do LDP, segundo nossa percepção, visando sempre ao melhor desempenho do aluno na produção de textos escritos.

Com a análise dos dados, notamos que as condições de produção do texto são favorecidas no LD. No entanto, foi possível perceber menor ocorrência de indicação do gênero e contexto externo ao longo da coleção, bem como pouca incidência de abordagem em espiral, questões que, como já colocamos antes, acreditamos ser de grande importância dentro do LDP e da vivência em sala de aula. Um aspecto que consideramos favorável é a incidência de uma considerável variedade de gêneros propostos para escrita.

Apesar de termos dito há pouco que houve pouca ocorrência no trabalho com algumas questões, o que pode ser, de certa forma, prejudicial ao aluno, já que todos eles colaboram de forma significativa para seu melhor desempenho, consideramos o LD, de forma geral, eficiente dentro do que lhe cabe e eficaz ao proporcionar material e orientar o professor na busca para formar alunos capazes para escrita. Na análise qualitativa, apontamos algumas atividades que ilustram de forma positiva os objetivos pretendidos neste estudo. Acreditamos que uma maior incidência de atividades como as que ilustram nossas considerações quantitativas só contribuiria com o aluno, ampliando ainda mais seus letramentos e sua capacidade de produzir textos significativos.

\section{REFERÊNCIAS BIBLIOGRÁFICAS}

ANTUNES, I. Aula de português: encontro e interação. São Paulo: Parábola Editorial, 2003.

BAKHTIN, M. Os gêneros do discurso. In Estética da criação verbal. São Paulo: Martins Fontes, 1979. p. 277-326. 
Volume 14, número 1, ano 2018.

BARDIN, L. Análise de Conteúdo. Lisboa: Edições 70, LDA, 2009.

BRASIL. Guia de livros didáticos: PNLD 2011: Língua Portuguesa. - Brasília: Ministério da Educação, Secretaria de Educação Básica, 2010.

CEREJA, W. R. Português: Linguagens, $6^{\circ}$ a $9^{\circ}$ ano/William Roberto Cereja, Thereza Cochar Magalhães. - 5. ed. reform. - São Paulo: Atual, 2009.

COSCARELLI, C. V. Gêneros textuais na escola. Veredas (UFJF), v. 2/2007, p. 5, 2007.

DA SILVA, S. R. Ensino de Produção Escrita de Gêneros da Ordem do Argumentar: o papel do livro didático de português e a atuação do professor. Campinas, SP : [s.n.], 2008.

- Gênero textual e tipologia textual: colocação sob dois enfoques teóricos. Soletras (UERJ), v. 20, p. 64-75, 2010.

DOLZ, J., NOVERRAZ, M. \& SCHNEUWLY, B. Sequências didáticas para o oral e a escrita: apresentação de um procedimento. In: SCHNEUWLY, B., DOLZ,J. et al. Gêneros orais e escritos na escola. Campinas: Mercado de Letras, 2010. p. 95-128.

DOLZ, J. e SCHNEUWLY, B. Gêneros e progressão em expressão oral e escrita: elementos para reflexões sobre uma experiência suíça (francófona). In: SCHNEUWLY, B., DOLZ, J. et al. Gêneros orais e escritos na escola. Campinas: Mercado de Letras, 2010, p. 41-70.

GERALDI, J. W. Portos de passagem. São Paulo: Martins Fontes, 2013.

MOITA LOPES, L. P. da. Oficina de linguística aplicada: a natureza social e educacional dos processos de ensino de línguas. Campinas: Mercado de Letras, 1996.

RAJAGOPALAN, K. Repensar o papel da linguística aplicada. In: MOITA LOPES, L. P da. (Org.). Por uma Linguística Aplicada Indisciplinar. São Paulo: Parábola, 2006. p. 149-166.

SCHNEUWLY, B. \& DOLZ, J. Os gêneros escolares - das práticas de linguagem aos objetos de ensino. In: SCHNEUWLY, B. \& DOLZ, J. et al. Gêneros orais e escritos na escola. Campinas: Mercado de Letras, 2010. p. 71-91.

SIGNOR, R. C. F. Os gêneros do discurso. Revista Gatilho (PPGL/ UFJF. Online), v. 7, p. $\mathrm{s} / \mathrm{p}, 2008$.

SILVA, E. T.;LAJOLO, M.;ZILBERMAN, R.;MACHADO, N. J.;DIETZSCH, M. J. M.; MOGILNIK, M.;MARCUSCHI, L. A.;DUARTE, L. R.;CAMPOS, R. B.;GUIMARÃES, R. B.;CAMARGO, L.;ROCCO, M. T. F.;BANDEIRA, P. Livro Didático: do ritual de passagem 
Volume 14, número 1, ano 2018.

à ultrapassagem. Em Aberto: Brasília DF, 1996. p. 11-15. 